\title{
PENGARUH PENDEKATAN ACCELERATED LEARNING MELALUI METODE WHOLE BRAIN TEACHING TERHADAP HASIL BELAJAR FISIKA SMP MATERI USAHA DAN PESAWAT SEDERHANA
}

\author{
Febri Ekasari $^{{ }^{*},}$ Effendi $^{1}$, Siti Anisatur Rofiqah ${ }^{1}$ \\ Program Studi Pendidikan Fisika STKIP Nurul Huda Sukaraja \\ ${ }^{*}$ Corresponden author: febri.ekasari0298@gmail.com
}

Article History:

Received: juli 21, 2020

Revised: september 12, 2020

Accepted: november 10, 2020

Published: desember 18, 2020

Keywords: $\quad$ Accelerated Learning Approach, Whole Brain Teaching Method, Conventional Method, Student Learning Outcomes

\begin{abstract}
This study aimed to determine whether there is an effect on the results of learning physics uses the accelerated learning approach with the whole brain teaching method on work and simple plane material at SMP Terpadu Pondok Pesantren Nurul Huda, 2020/2021 academic year. This research was a quantitative research. The population in this study were students of class VIII at the Nurul Huda Integrated Junior High School, which consisted of 5 classes. The sample in this study was carried out randomly. The experimental class conducted learning by applying the accelerated learning approach through the whole brain teaching method, while the control class used conventional methods. Data collection techniques to determine student learning outcomes using test instruments, and testing the hypothesis using the t-test. Based on the test results, the experimental class average score is 73 and the control class average is 71. The t test results show that tcount $=2.53$ and ttable $=1.68$, so that $H O$ is rejected and Ha is accepted. So, it can be concluded that there is a significant effect or difference in the average score between the class with accelerated learning approach with the whole brain teaching method and the class with conventional methods.
\end{abstract}

\begin{abstract}
Abstrak: Penelitian ini bertujuan untuk mengetahui apakah terdapat pengaruh hasil belajar fisika siswa kelas VIII yang pembelajarannya menggunakan pendekatan accelerated learning melalui metode whole brain teaching dengan metode konvensional pada materi usaha dan pesawat sederhana di SMP Terpadu Pondok Pesantren Nurul Huda tahun pembelajaran 2020/2021. Penelitian ini termasuk penelitian jenis kuantitatif. Populasi dalam penelitian ini siswa kelas VIII di SMP Terpadu Pondok Pesantren Nurul Huda yang terdiri dari 5 kelas. Pengambilan sampel dalam penelitian ini dilakukan secara acak. Kelas eksperimen yang pembelajarannya menggunakan pendekatan accelerated learning melalui metode whole brain teaching, sedangkan kelas kontrol pembelajarannya menggunakan metode konvensional. Teknik pengumpulan data untuk mengetahui hasil belajar siswa menggunakan tes, dan pengujian hipotesisnya menggunakan uji-t. Berdasarkan hasil belajar siswa setelah diadakan tes diperoleh nilai rata-rata kelas eksperimen 73 dan nilai rata-rata kelas kontrol 71 . Terdapat pengaruh hasil belajar yang signifikan antara siswa yang pembelajarannya menggunakan metode konvensional. Hal itu dapat dilihat dari $t_{\text {hitung }}=2,53$ dan $t_{\text {tabel }}=1,68$, sehingga $H_{0}$ ditolak dan $H_{a}$ diterima. Jadi, dapat disimpulkan bahwa terdapat pengaruh hasil belajar yang signifikan antara siswa yang pembelajarannya menggunakan pendekatan accelerated learning melalui metode whole brain teaching dan siswa yang pembelajarannya menggunakan metode konvensional.
\end{abstract}




\section{PENDAHULUAN}

Pendidikan pada dasarnya yaitu usaha untuk menumbuh kembangkan potensi sumber daya manusia dengan cara mendorong dan memfasilitasi kegiatan belajar siswa (Krismiyati, 2017). Proses kegiatan pembelajaran termasuk rangkaian kegiatan komunikasi antar manusia yakni antara orang yang belajar disebut siswa dan orang yang mengajar disebut guru. Guru salah satu komponen yang sangat menentukan keberhasilan siswa dalam belajar. Oleh karena itu, guru harus selalu berusaha dan berinovasi untuk menemukan strategi, metode, model, dan pendekatan yang tepat dalam pembelajaran (Rofiqah, Widayanti, \& Rozaqi, 2020).

Berdasarkan hasil observasi yang dilakukan di SMP Terpadu Pondok Pesantren Nurul Huda kelas VIII dengan menyebarkan angket kepada siswa diperoleh data bahwa dari 20 siswa, 16 siswa mengatakan bahwa fisika itu sulit dan kurang berminat. Sedangkan untuk keaktifan, dari 20 siswa hanya 8 siswa yang aktif ketika guru menyampaikan materi menggunakan metode ceramah. Dari 20 siswa, 10 siswa mengatakan jika merasa jenuh pada saat pelajaran IPA khususnya materi fisika berlangsung (Ekasari, 2020).

Selain dengan angket, peneliti juga melakukan wawancara dengan guru mata pelajaran IPA kelas VIII yang mengatakan bahwa kemampuan siswa kelas VIII dalam mengikuti pembelajaran IPA khususnya materi fisika berkisar 65\%. Kurangnya ketersediaan buku paket IPA dan juga fasilitas internet di SMP Terpadu Pondok Pesantren Nurul Huda belum ada sehingga siswa kesulitan untuk mencari sumber belajar lainnya, karena keterbatasan sarana dan prasarana yang ada. Pendekatan yang sering digunakan pada mata pelajaran IPA kelas VIII di SMP Terpadu Pondok Pesantren Nurul Huda tahun pembelajaran 2020/2021 yaitu pendekatan scientific learning. Sedangkan metode yang sering digunakan yaitu metode ceramah, meskipun terkadang memakai metode demonstrasi dan penugasan (Ekasari, 2020).

Oleh karena itu, diperlukan salah satu upaya untuk mengatasi permasalahan dalam hal ini, yaitu dengan menggunakan pendekatan dan metode pembelajaran yang lebih efektif, yang dapat meningkatkan minat, semangat, kemampuan untuk dapat bekerja bersama teman dalam menemukan suatu permasalahan, dan kegembiraan siswa serta dengan sendirinya diharapkan dapat meningkatkan hasil belajar siswa. Salah satu pendekatan yang dapat memicu siswa ikut serta secara aktif dalam pembelajaran yaitu pendekatan accelerated learning.

Pendekatan accelerated learning termasuk salah satu pendekatan yang mampu meningkatkan hasil belajar siswa dan dapat memicu siswa ikut serta secara aktif dalam pembelajaran (Rachmita, Hariyadi, \& Asyiah, 2013). Menurut Rose dan Nichole menyatakan bahwa accelerated learning yaitu kemampan menyerap dan memahami informasi baru dengan cepat dan menguasai informasi tersebut. Pendekatan ini dapat membuat siswa belajar lebih menyenangkan dan lebih cepat (Rose \& Nicholl, 2002). Materi yang sulit dibuat menjadi mudah, sederhana, sehingga tidak menjadi kejenuhan dalam belajar. Accelerated Learning membuat belajar menyenangkan dan benar-benar sangat mementingkan hasil (Rachmita et al., 2013). Karena 
keberhasilan belajar tidak ditentukan atau diukur dari lamanya siswa duduk untuk belajar tetapi ditentukan oleh kualitas cara belajar siswa.

Ada enam langkah dasar yang dapat membantu ketercapaian proses pembelajaran dan kualitas cara belajar siswa, yaitu: Motivating your mind, Acquiring the information, Searching out the meaning, Triggering the memory, Exhibiting what you know, Reflecting how you've learned. Keenam langkah dasar tersebut dapat diingat dengan mudah menggunakan singkatan MASTER (Rose \& Nicholl, 2002). Selain itu diperlukan sebuah metode pembelajaran yang tepat sebagai sarana dalam menerapkan pendekatan accelerated learning, yaitu dengan menerapkan metode whole brain teaching.

Metode whole brain teaching ini cukup menarik dibandingkan metode lainnya, karena metode ini mampu menarik perhatian siswa melalui perintahperintah dan respon-respon sederhana dengan suatu ungkapan bahasa Inggris sehingga siswa lebih terfokus pada materi yang diberikan dan dapat diterapkan untuk hampir semua mata pelajaran (Setyaningrum, Winanti, \& Hari, 2020). Banyak siswa yang merasa senang ketika guru menggunakan metode yang menyenangkan. Untuk itu, metode ini dinilai sangat tepat diterapkan dalam pembelajaran IPA kelas VIII yaitu pada materi usaha dan pesawat sederhana.

Materi tentang usaha dan pesawat sederhana ini, banyak terdapat rumusrumus dan konsep. Oleh karena itu, seringkali sebelum mempelajarinya siswa kurang berminat pada materi ini. Sehingga diperlukan suatu pendekatan yang membuat siswa mudah memahami selama mempelajari materi tersebut. Pada prosesnya, untuk membantu mengingat dan memahami rumus-rumus serta materi yang ada dalam usaha dan pesawat sederhana, dapat dilakukan dengan menggunakan pendekatan serta metode yang menyenangkan dan dapat membuat suasana belajar lebih bersemangat. Pendekatan dan metode tersebut yaitu pendekatan accelerated learning dan metode whole brain teaching. Penggabungan antara pendekatan accelerated learning dengan metode whole brain teaching diharapkan mampu memberikan motivasi dan menarik siswa untuk berperan aktif dalam pembelajaran sehingga pembelajaran menjadi lebih efektif dan dapat meningkatkan hasil belajar siswa.

Pada penelitian sebelumnya penerapan pendekatan accelerated learning dengan modalitas otak dapat meningkatkan hasil belajar siswa, dengan pengajaran dapat melibatkan emosi, seluruh tubuh, semua indra dan segenap pribadi yang tidak diperoleh siswa pada kelas kontrol (Rachmita et al., 2013). Penerapan metode whole brain teaching dapat meningkatkan motivasi belajar siswa pada kegiatan pembelajaran sangatlah efektif karena siswa tidak hanya duduk diam mendengarkan guru, namun mereka juga ikut terlibat aktif dalam kegiatan pembelajaran (Isnawati, Kendek, \& Syamsu, 2015).

Beda peneliti dengan dua penelitian sebelumnya, fokus penelitian ini ingin mengetahui pengaruh pendekatan accelerated learning melalui metode whole brain teaching terhadap hasil belajar fisika siswa. 


\section{METODE PENELITIAN}

Penelitian ini dilakukan di SMP Terpadu Pondok Pesantren Nurul Huda pada bulan September 2020. Pengambilan sampel menggunakan teknik cluster sampling, kelas VIII.D sebagai kelompok ekperimen dan kelas VIII.C sebagai kelompok kontrol tahun pembelajaran 2020/2021. Desain penelitian yang digunakan pada penelitian ini posttest only control design. Dalam desain ini terdapat dua kelompok yang masingmasing dipilih secara random (Sugiyono, 2018). Pada kedua kelompok tidak diawali dengan pretest. Pengukurannya hanya dilakukan setelah pemberian perlakuan selesai seperti pada tabel 1 .

Tabel 1. Desain Penelitian

\begin{tabular}{|c|c|c|c|}
\hline Subyek & Pre-Test & Perlakuan & Post-Test \\
\hline $\begin{array}{c}\text { Eksperi } \\
\text { men }\end{array}$ & - & $\mathrm{X}_{1}$ & $\mathrm{O}_{1}$ \\
\hline Kontrol & - & $\mathrm{X}_{2}$ & $\mathrm{O}_{2}$ \\
\hline
\end{tabular}

Keterangan:

$\mathrm{X}_{1}=$ Perlakuan untuk kelompok eksperimen yang menggunakan pendekatan accelerated learning melalui metode whole brain teaching

$\mathrm{X}_{2}=$ Perlakuan untuk kelompok kontrol yang menggunakan metode konvensional

$\mathrm{O}_{1}=$ Post-Test untuk kelompok eksperimen yang menggunakan pendekatan accelerated learning melalui metode whole brain teaching

$\mathrm{O}_{2}=$ Post-Test untuk kelompok kontrol yang menggunakan metode konvensional

Adapun pengumpulan data dalam penelitian ini yaitu tes hasil belajar yang bertujuan untuk mengetahui hasil belajar siswa. Tes hasil belajar ini berupa tes tertulis dalam bentuk pilihan ganda. Teknik analisis data dalam penelitian ini dilakukan dengan cara menghitung ratarata (mean), standar deviasi, dan menentukan tingkat kesukaran soal dengan kategori tinggi, sedang, dan rendah. Analisis data digunakan untuk melihat gambaran hasil belajar siswa dalam pembelajaran fisika setelah proses pembelajaran dilakukan. Selain itu, dilakukan pengujian hipotesis untuk mengetahui ada pengaruh atau tidak.

\section{HASIL DAN PEMBAHASAN}

Hasil penelitian dalam penerapan pendekatan accelerated learning melalui metode whole brain teaching dapat meningkatkan hasil belajar fisika siswa kelas VIII SMP Terpadu Pondok Pesantren Nurul Huda. Sehingga diperoleh hasil posttest untuk kelompok eksperimen, skor terendah pada interval 55 - 60 sebanyak 2 siswa, skor dengan perolehan terbanyak terdapat pada interval 75 - 80 sebanyak 10 siswa, dan 2 siswa memperoleh skor tertinggi pada interval 85 - 90. Untuk kelompok kontrol, skor terendah pada interval $45-50$ sebanyak 2 siswa, skor dengan perolehan terbanyak terdapat pada interval $55-60$ sebanyak 11 siswa, dan 1 siswa memperoleh skor tertinggi pada interval 75 - 80. Ukuran pemusatan dan penyebaran data hasil posttest kelompok eksperimen dan kelompok kontrol berupa rata-rata (mean), dan standar deviasi dapat dilihat pada tabel 2 .

Tabel 2. Ukuran Pemusatan dan Penyebaran Data Hasil Posttest Kelompok Eksperimen dan Kelompok Kontrol

\begin{tabular}{|c|c|c|}
\hline Data & $\begin{array}{c}\text { Kelompok } \\
\text { Eksperimen }\end{array}$ & $\begin{array}{c}\text { Kelompok } \\
\text { Kontrol }\end{array}$ \\
\hline Nilai terendah & 55 & 45 \\
\hline Nilai tertinggi & 90 & 80 \\
\hline Rata-rata (mean) & 73 & 71 \\
\hline Standar Deviasi & 8,25 & 7,56 \\
\hline
\end{tabular}

Analisis data penelitian untuk menentukan kategori tinggi, sedang, dan 
rendah kelompok eksperimen dan kelompok kontrol dengan cara membuat daftar distribusi frekuensi, menghitung nilai rata-rata (mean), standar deviasi, dan menentukan kategori tinggi, sedang, dan rendah. Berdasarkan hasil perhitungan yang diperoleh persentase hasil belajar fisika siswa ditinjau dari nilai kategori tinggi, sedang, dan rendah yang disajikan pada tabel 3 .

Tabel 3. Persentase Hasil Belajar Siswa Ditinjau dari Persentase Nilai Kategori Tinggi, Sedang, dan Rendah

\begin{tabular}{|c|c|c|c|c|c|}
\hline \multirow{2}{*}{ No } & Kategori & $\begin{array}{c}\text { Jumlah } \\
\text { siswa }\end{array}$ & $\begin{array}{c}\text { Persentase } \\
(\%)\end{array}$ & $\begin{array}{c}\text { Jumlah } \\
\text { siswa }\end{array}$ & $\begin{array}{c}\text { Persentase } \\
(\%)\end{array}$ \\
\hline 1 & Tinggi & 6 & $26,09 \%$ & 1 & $4,35 \%$ \\
\hline 2 & Sedang & 15 & $65,22 \%$ & 9 & $39,13 \%$ \\
\hline 3 & Rendah & 2 & $8,70 \%$ & 13 & $56,52 \%$ \\
\hline
\end{tabular}

Sebelum melakukan uji hipotesis menggunakan uji-t terlebih dahulu dilakukan uji prasyarat analisis data yaitu uji normalitas dan uji homogenitas. Uji normalitas dilakukan untuk mengetahui apakah sampel yang diteliti berdistribusi normal atau tidak. Uji normalitas pada penelitian ini menggunakan uji chi kuadrat.

a. Jika $X^{2}$ hitung $>X^{2}$ tabel maka distribusi data tidak normal.

b. Jika $X_{\text {hitung }}^{2}<X^{2}$ tabel maka distribusi data normal

Hasil uji normalitas posttest kelompok eksperimen dan kelompok kontrol dapat dilihat pada tabel 4 .

Tabel 4. Hasil Uji Normalitas Data Posttest Kelompok Eksperimen dan Kelompok Kontrol

\begin{tabular}{|c|c|c|}
\hline Statistik & $\begin{array}{c}\text { Kelompok } \\
\text { Eksperimen }\end{array}$ & $\begin{array}{c}\text { Kelompok } \\
\text { Kontrol }\end{array}$ \\
\hline$X^{2}{ }_{\text {hitung }}$ & 7,25 & 4,08 \\
\hline$X^{2}{ }_{\text {tabel }}$ & 11,07 & 11,07 \\
\hline Keputusan & $\begin{array}{c}X^{2}{ }_{\text {hitung }}<X^{2} \text { tabel } \\
\text { distribusi data } \\
\text { normal }\end{array}$ & $\begin{array}{c}X^{2}{ }_{\text {hitung }}<X^{2}{ }_{\text {tabel }} \\
\text { distribusi data } \\
\text { normal }\end{array}$ \\
\hline
\end{tabular}

Berdasarkan tabel hasil uji normalitas di atas dapat diketahui bahwa data hasil posttest kelompok eksperimen dan kelompok kontrol berdistribusi normal karena memenuhi kriteria yaitu $X^{2}$ hitung < $X^{2}$ tabel.

Setelah kedua sampel kelompok dinyatakan berdistribusi normal, selanjutnya dilakukan pengujian homogenitas. Pengujian homogenitas dilakukan untuk mengetahui apakah data penelitian memiliki varians yang homogen atau tidak. Dalam penelitian ini uji homogenitas dilakukan berdasarkan uji kesamaan varians kedua kelas, menggunakan uji-F pada taraf signifikan $(\alpha)=0,05$ dengan kriteria pengujian yaitu: jika $F_{\text {hitung }}<F_{\text {tabel }}$ maka data dari kedua kelompok mempunyai varians yang homogen. Hasil uji homogenitas posttest kedua kelompok sampel penelitian dapat dilihat pada tabel 5 .

Tabel 5. Hasil Uji Homogenitas Data Posttest

\begin{tabular}{|c|c|c|}
\hline Statistik & $\begin{array}{c}\text { Kelompok } \\
\text { Eksperimen }\end{array}$ & $\begin{array}{c}\text { Kelompok } \\
\text { Kontrol }\end{array}$ \\
\hline $\mathrm{S}^{2}$ & 8,25 & 7,56 \\
\hline $\mathrm{F}_{\text {hitung }}$ & \multicolumn{2}{|c|}{1,09} \\
\hline $\mathrm{F}_{\text {tabel }}$ & \multicolumn{2}{|c|}{2,05} \\
\hline Keputusan & \multicolumn{2}{|c|}{ Homogen } \\
\hline
\end{tabular}

Berdasarkan tabel di atas, untuk data posttest didapat $\mathrm{F}_{\text {hitung }}=1,09$ dan $\mathrm{F}_{\text {tabel }}=$ 2,05. Dari data tersebut didapatkan $F_{\text {hitung }}$ $<\mathrm{F}_{\text {tabel, }}$ maka dapat diketahui data hasil belajar dari kedua sampel tersebut mempunyai varians yang homogen.

Setelah dilakukan uji prasyarat analisis data, diketahui bahwa data hasil belajar kedua kelompok pada penelitian ini berdistribusi normal dan homogen. Sehingga pengujian data hasil belajar kedua kelompok dilanjutkan pada analisis data berikutnya yaitu uji hipotesis menggunakan uji-t. Kriteria pengujian, yaitu jika $t_{\text {hitung }}<\mathrm{t}_{\text {tabel }}$ maka $\mathrm{H}_{0}$ diterima $\mathrm{H}_{\mathrm{a}}$ ditolak. Jika thitung $>\mathrm{t}_{\text {tabel }}$ maka $\mathrm{H}_{0}$ ditolak $\mathrm{H}_{\mathrm{a}}$ diterima. Berdasarkan hasil perhitungan, diperoleh $t_{\text {hitung }}$ sebesar 2,53. Pada taraf signifikan $(\alpha)=0,05$ dan $\mathrm{df}=$ $23+23-2=44$, diperoleh nilai $t_{\text {tabel }}$ sebesar 
1,68. Berikut pengujian hipotesis data hasil belajar dapat dilihat pada tabel 6 .

Tabel 6. Hasil Uji Hipotesis

\begin{tabular}{|c|c|c|}
\hline Statistik & $\begin{array}{c}\text { Kelompok } \\
\text { Eksperimen }\end{array}$ & $\begin{array}{c}\text { Kelompok } \\
\text { Kontrol }\end{array}$ \\
\hline $\mathrm{N}$ & 23 & 23 \\
\hline $\bar{X}$ & 73 & 71 \\
\hline $\mathrm{S}^{2}$ & 8,25 & 7,56 \\
\hline $\mathrm{t}_{\text {hitung }}$ & \multicolumn{2}{|c|}{2,53} \\
\hline $\mathrm{t}_{\text {tabel }}$ & \multicolumn{2}{|c|}{1,68} \\
\hline Keputusan & \multicolumn{2}{|c|}{ Terdapat pengaruh } \\
\hline
\end{tabular}

Berdasarkan tabel 6, tampak bahwa nilai posttest kedua kelompok setelah diberi perlakuan yang berbeda yaitu didapat $t_{\text {hitung }}>t_{\text {tabel }}$ yaitu $2,53>1,68$ sehingga hipotesis nol $\left(\mathrm{H}_{0}\right)$ ditolak dan hipotesis alternatif $\left(\mathrm{H}_{\mathrm{a}}\right)$ diterima. Dengan diterimanya $\mathrm{H}_{\mathrm{a}}$ pada pengujian hipotesis tersebut, dapat dipahami bahwa penelitian ini dapat menguji kebenaran hipotesis yaitu terdapat pengaruh yang signifikan dalam pendekatan accelerated learning melalui metode whole brain teaching terhadap hasil belajar fisika siswa kelas VIII SMP Terpadu Pondok Pesantren Nurul Huda tahun pembelajaran 2020/2021. Hal tersebut menunjukkan rata-rata hasil belajar fisika kelompok eksperimen lebih baik dari pada rata-rata hasil belajar fisika kelompok kontrol. Adapun kurva daerah penerimaan dan penolakan hipotesis nol $\left(\mathrm{H}_{0}\right)$ seperti pada gambar 1.

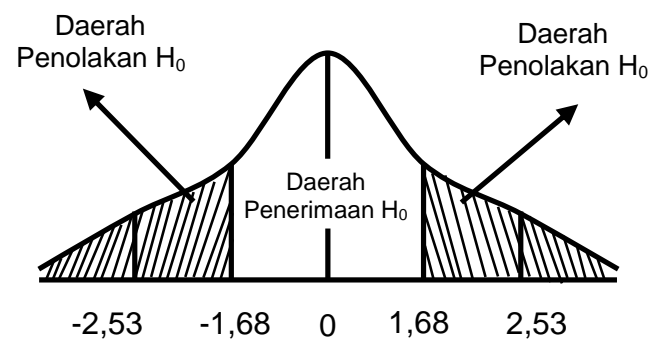

Gambar 1. Kurva Daerah Penerimaan dan Penolakan Hipotesis Nol

Pada hasil belajar fisika memperlihatkan bahwa siswa yang diberi perlakuan dengan pendekatan accelerated learning melalui metode whole brain teaching pada saat proses pembelajaran, menunjukkan hasil belajar yang lebih tinggi dari pada hasil belajar siswa yang diberi perlakuan dengan metode konvensional. Hal ini terlihat dari nilai $t_{\text {hitung }}>t_{\text {tabel }}$. Selain itu, perolehan nilai $t_{\text {hitung }}>t_{\text {tabel }}$ mengindikasikan adanya pengaruh yang cukup signifikan antara kelompok eksperimen dan kelompok kontrol. Perbedaan nilai tersebut dikarenakan adanya perbedaan perlakuan dalam proses pembelajaran antara kedua kelompok, seperti pada tabel 7.

Tabel 7. Perbedaan Perlakuan dalam Proses Pembelajaran pada Kelompok Eksperimen dan Kelompok Kontrol Usaha dan Pesawat Sederhana

\begin{tabular}{|c|c|}
\hline $\begin{array}{c}\text { Pendekatan Accelerated } \\
\text { Learning melalui Metode } \\
\text { Whole Brain Teaching }\end{array}$ & $\begin{array}{c}\text { Metode } \\
\text { Konvensional }\end{array}$ \\
\hline
\end{tabular}

1. Guru memberikan 1. Guru motivasi dengan menjelaskan memperlihatkan gambaran-gambaran tentang materi yang akan disampaikan.

Guru memberikan 2. Guru gambaran tentang memberikan materi yang akan contoh soal disampaikan dengan yang terdapat bertanya kepada siswa.

3. Guru membentuk kelompok besar yang 3 terdiri dari 4 orang siswa, dan di dalam kelompok besar terdiri dari kelompok kecil yang berjumlah 2 orang.

4. Guru memfokuskan perhatian dan konsentrasi siswa agar terpusat pada guru dengan sapaan classyes Siswa mendengarkan apa yang dijelaskan guru

5. Guru menjelaskan tentang usaha dan pesawat sederhana dengan gerakan 6 . bermakna (gesture)

6. Guru meminta siswa untuk mengajarkan materi tentang usaha dan pesawat sederhana. contoh soa
yang terdapa pada materi tersebut.

\section{Guru} memberikan kesempatan kepada siswa untuk

bertanya.

4. Guru memberikan siswa soal untuk dijawab dan dikumpulkan.

Guru memeriksa dan membahas soal yang telah dikerjakan siswa.

Guru memberikan pertanyaan kepada siswa, 


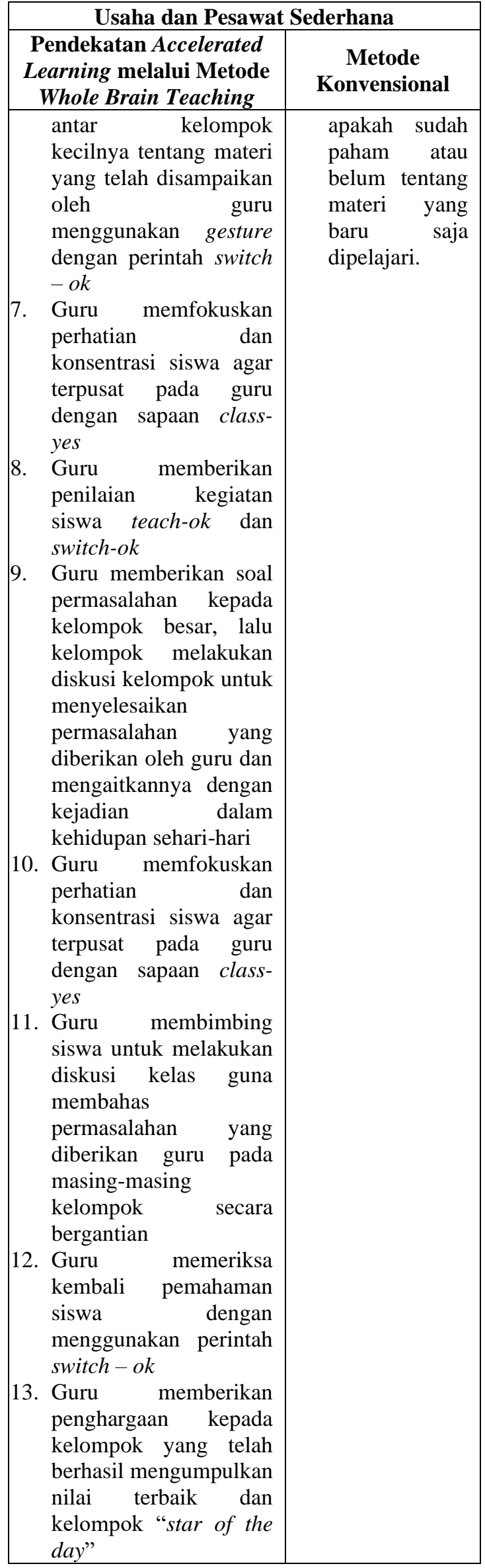

Pada proses penerapan pendekatan accelerated learning, sebelum memulai pembelajaran siswa terlebih dahulu dibawa pada keadaan rileks, percaya diri, dan termotivasi agar dapat belajar dengan baik dengan cara melakukan senam otak. Kemudian, pembelajaran harus berlangsung menyenangkan dengan menggunakan keterlibatan siswa baik secara fisik maupun mental. Penggunaan metode whole brain teaching, bertujuan untuk menarik perhatian siswa. Dengan perintah-perintah dan respon-respon sederhana yang menggunakan ungkapan dalam bahasa Inggris. Sehingga membantu menciptakan proses pembelajaran yang menyenangkan. Dalam pendekatan accelerated learning melalui metode whole brain teaching termasuk cara untuk mendatangkan kegembiraan dalam proses pembelajaran dan membuat siswa lebih fokus pada materi yang diberikan.

Proses pembelajaran pada kelompok kontrol yang menggunakan metode konvensional, menunjukkan guru lebih berperan aktif dari pada siswa. Pembelajaran ini juga menekankan pada bagaimana siswa dapat memahami konsep yang diajarkan. Tanpa mempedulikan bagaimana kesiapan siswa secara mental sebelum belajar, minat siswa saat dan setelah belajar, juga gaya belajar siswa. Penyampaian materi yang hanya menggunakan metode ceramah membuat siswa kurang tertarik dan tidak terfokus perhatiannya. Siswa tidak terfokus pada apa yang disampaikan oleh guru. Siswa hanya memperoleh informasi berdasarkan penjelasan guru. Siswa cenderung pasif dan tidak memperoleh pengalamannya sendiri. Hal tersebut berakibat pada hasil belajar yang kurang maksimal.

Berdasarkan uraian di atas, maka dapat dipahami bahwa penggunaan pendekatan accelerated learning melalui metode whole brain teaching telah memberikan pengaruh yang signifikan terhadap hasil belajar siswa. Hal ini 
didukung oleh hasil penelitian dari (Wijaya \& Irianti, 2017), yang menunjukkan bahwa pembelajaran menggunakan Whole Brain Teaching dapat diterapkan serta terlaksana dengan baik. Peserta didik berpendapat bahwa pembelajaran menggunakan Whole Brain Teaching lebih menyenangkan, secara umum penyampaian gesture yang digunakan saat pembelajaran mampu membantu dalam memahami konsep dan membuat daya ingat mereka lebih lama.

Penelitian lain menyatakan terdapat perbedaan hasil belajar peserta didik, menggunakan metode Whole Brain Teaching nilai yang diperoleh lebih tinggi dibandingkan dengan menggunakan metode konvensional. Karena pada metode Whole Brain Teaching peserta didik menjadi lebih fokus dengan pembelajaran yang dipadukan antara visual, verbal dan gerak tubuh (Kusuma, Rahmawati, \& Ramadoni, 2017). Selain itu, penerapan pendekatan accelerated learning dengan metode whole brain teaching menunjukkan bahwa nilai ratarata hasil belajar yang pembelajarannya menggunakan pendekatan accelerated learning dengan metode whole brain teaching lebih baik dari metode konvensional.

\section{SIMPULAN DAN SARAN}

Berdasarkan analisis data serta pengujian hipotesis hasil penelitian tentang pengaruh pendekatan accelerated learning melalui metode whole brain teaching terhadap hasil belajar fisika siswa kelas VIII SMP Terpadu Pondok Pesantren Nurul Huda tahun pembelajaran 2020/2021 yang sudah dilaksanakan oleh peneliti, Hasil perhitungan uji hipotesis menunjukkan $t_{\text {hitung }}>t_{\text {tabel }}$ yaitu $2,53>$ 1,68. Maka dapat disimpulkan bahwa terdapat pengaruh yang signifikan antara siswa yang pembelajarannya menggunakan pendekatan accelerated learning melalui metode whole brain teaching, dengan siswa yang pembelajarannya menggunakan metode konvensional. Hasil belajar fisika siswa yang menggunakan pendekatan accelerated learning melalui metode whole brain teaching lebih baik dibandingkan hasil belajar fisika siswa yang menggunakan metode pembelajaran konvensional.

Berdasarkan penelitian yang telah dilakukan, penulis menyarankan bagi peneliti selanjutnya diharapkan untuk lebih paham melihat kondisi siswa, dan dapat memanajemen waktu dengan baik agar lebih efektif dan efisien sehingga tujuan penelitian dapat tercapai.

\section{DAFTAR PUSTAKA}

Ekasari, F. (2020). Wawancara Hasil Belajar Di SMP Terpadu Pondok Pesantren Nurul Huda. OKU Timur, Palembang.

Isnawati, I., Kendek, Y., \& Syamsu, S. (2015). Pengaruh Metode Pembelajaran Whole Brain Teaching Terhadap Hasil Belajar Ipa Siswa Kelas Viii Smp Negeri 18 Palu. JPFT (Jurnal Pendidikan Fisika Tadulako Online), 3(2), 24-28. https://doi.org/10.22487/j25805924.2 015.v3.i2.5110

Krismiyati. (2017). Pengembangan Sumber Daya Manusia dalam Meningkatkan Kualitas Pendidikan di SD Negeri Inpres Angkasa Biak. Jurnal Office, 3(1), 43-50.

Kusuma, A. P., Rahmawati, N. K., \& Ramadoni. (2017). The Application of the Accelerated Learning Cycle, Brain-based Learning Model, and Direct Instruction Model toward Mathematical Reasoning in Terms of Mathematical Communication. AlJabar: Jurnal Pendidikan Matematika, 11(1), 21-28. Retrieved 
from

http://ejournal.radenintan.ac.id/index .php/al-jabar/article/view/2014/1564

Rachmita, Hariyadi, S., \& Asyiah, I. N. (2013). Penerapan Pendekatan Accelerated Learning Dengan Modalitas Otak Terhadap Aktivitas Dan Hasil Belajar Siswa (Siswa Kelas VIII SMP Negeri 9 Jember). Pancaran, 2(4), 129-141.

Rofiqah, S. A., Widayanti, \& Rozaqi, A. (2020). Thinking Aloud Pair Problem Solving (TAPPS) Method : The Effect of Understanding Physics Concepts and Communication in High Schools in Indonesia. In Young Scholar Symposium on Science Education and Environment 2019 (pp. 1-8). Bandar Lampung: Journal of Physics: Conference Series. https://doi.org/10.1088/17426596/1467/1/012066

Rose, C., \& Nicholl, M. J. (2002). Accelerated Learning For The 21st Century: Cara Belajar Cepat Abad $X X I$. Bandung: Nuansa.

Setyaningrum, N. W., Winanti, T., \& Hari, N. (2020). The Freedom of Learning with Accelerated Learning Through the Utilization of SaviBased Student's Activity Sheet (LKPD) ( Somatic , Auditorial , Visual and Intellectual ) In Maritime Economic Material. Jurnal Education and Development, 8(2), 116-119.

Sugiyono. (2018). Metode Penelitian Kuantitatif, Kualitatif dan $R \& D$. bandung: Penerbit Alfabeta.

Wijaya, E. M. S., \& Irianti, N. P. (2017). Whole Brain Teaching sebagai Desain Pembelajaran Matematika yang Kreatif. MUST: Journal of Mathematics Education, Science and Technology, 2(2), 196-207.
Mukrima, Syifa S. 2014. 53 Metode Belajar dan Pembelajaran. Bandung: Universitas Pendidikan Indonesia. 